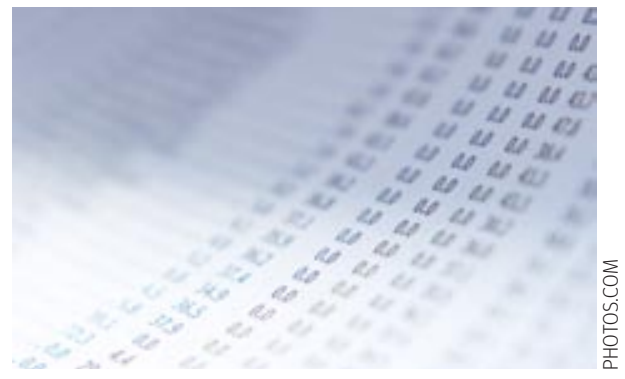

\section{MOVING BEYOND DEPRESSION}

\section{The researcher's credo}

Lenzer and Brownlee have hit the nail on the head regarding the important issue of data access. ${ }^{1}$ We owe all human subjects who volunteer for behavioural and medical research more than they have been getting. Foryears the top scientific journals have required that all clinical trials be publicly registered before data collection begins, in order to be eligible for publication. This was an important step designed to reduce publication bias, but it did not go far enough. The recent FDA Amendments Act mandating public access to data summaries is another step in the right direction, but, as Lenzer and Brownlee say, this too may not go far enough. Several examples from the psychopharmacology literature have shown that nothing short of total public access to raw human subject data on efficacy and safety will be enough to ensure that data are independently and thoroughly evaluated. ${ }^{2}{ }^{3}$ Issues of distorted or selective publication continue to corrupt our ostensible scientific database. ${ }^{45}$

We urge all institutional review boards to require that, in exchange for the privilege of doing human subject research, researchers make their raw data (not just summaries of the data) accessible (without identifying information) within a reasonable period of time via the internet or in some other suitable fashion. We believe scientists owe this unfettered access to all participants who have ever volunteered for a scientific study with the hope, belief, and promise that their sacrifices would help science advance. We offer the following brief universal commitment to human subjects that can be used by any institutional review board in the world.

"I agree, in exchange for the privilege of doing research with human subjects, to not only register the trial in a publicly accessible clinical trials database, but also to make summaries of the primary results and the actual raw data internet accessible (without identifying information) within 1 year of collecting data on the last human subject, or within 2 years after the start of the study, whichever is sooner. This is my commitment to all human subjects who volunteer with the hope, expectation and promise that their efforts and sacrifices will result in independently verifiable contributions to science. I recognize that failure to follow through on this commitment may jeopardize approval for any future research protocols in which I may participate."

David 0 Antonuccio professor of psychiatry and behavioral sciences, University of Nevada School of Medicine, 401 W 2nd St, Suite 216, Reno, NV 89503, USA oliver2@aol.com David Healy professor, North Wales Department of

Psychological Medicine, Cardiff University, Cardiff LL57 2PW Competing interests: See bmj.com

1 Lenzer J, Brownlee S. Antidepressants. An untold story? BMJ 2008;336:532. (8 March.)

2 Antonuccio DO, Danton WO, McClanahan TM. Psychology in the prescription era: building a firewall between marketing and science. Am Psychol 2003;58:1028-43.

3 Healy D. Let them eat Prozac: the unhealthy relationship between the pharmaceutical industry and depression. New York: New York University Press, 2004.

4 Kirsch I, Deacon B], Huedo-Medina TB, Scoboria A, Moore TJ, Johnson BT. Initial severity and antidepressant benefits: A meta-analysis of data submitted to the Food and Drug Administration. PLoS Med 2008;5:260-8.

5 Turner EH, Matthews AM, Linardatos E, Tell RA, Rosenthal R. Selective publication of antidepressant trials and its influence on apparent efficacy. NEngl/Med 2008;358:252-60.

\section{Excessively closed science hurts}

I would like to add to Lenzer and Brownlee's reporting of my comments on how excessively closed science can hurt physicians and patients. ${ }^{1}$

Statistician Michael Bracken led the NASCIS 2 and 3 studies of high dose steroids in acute spinal cord injury. ${ }^{2}$ The National Institute of Neurological Disorders and Stroke conducted a public campaign in advance of the scientific publication of NASCIS 2 on 17 May 1990. The institute sent a fax on 13 April 1990 to some 19000 emergency room physicians and hospitals, after a press release had resulted in coverage by the New York Times and the Chicago Tribune on 31 March 1990, by Science News on 7 April 1990, by Newsweek on 9 April 1990.

This led to widespread use of steroids, off label. No application for regulatory approval for this indication was completed, and no agency ever approved it. Surgeons report that methylprednisolone is administered from fear of litigation, not belief in efficacy. ${ }^{3}$ Bracken reinforced this fear by testifying against physicians; he was deposed on 9 June 1998 in Civil Action File No 96A-7768-6, Superior Court of Fulton County, GA.

We have criticised NASCIS science. ${ }^{4}$ The later guidelines for the management of acute cervical spine and spinal cord injuries from the American Association of Neurological Surgeons and the Congress of Neurological Surgeons (AANS/ CNS) ${ }^{5}$ rated the NASCIS publications as evidence class III, citing flaws in study design, data presentation, interpretation, and analysis. They listed steroid treatment only as an "option."

The lack of demonstrated benefit must be weighed against documented risks. The CRASH trial showed a $3 \%$ greater mortality when corticosteroids were given to a multitrauma group with head injury. If this increased death rate held in $\mathrm{SCl}$, then 5000 extra patients may have died in the US since 1990.

Yet it's difficult to stop the momentumespecially when primary data are unavailable for independent review.

Fred H. Geisler director, Illinois Neuro-Spine Center, 2020 Ogden Ave, Suite 335, Aurora, IL 60504

fgeisler@gmail.com

Competing interests: None declared.

1 Lenzer J, Brownlee S. Antidepressants. An untold story? BMJ 2008;336:532. (8 March.)

2 Bracken MB, Shepard MJ, Collins WFIr, Holford TR, Baskin DS, Eisenberg HM, et al. A randomized, controlled trial of methylprednisolone or naloxone in the treatment of acute spinal-cord injury. Results of the second national acute spinal cord injury study. N EnglJ Med 1990;322:1405-11.

3 EckJC, Nachtigall D, Humphreys SC, Hodges SD. Questionnaire survey of spine surgeons on the use of methylprednisolone for acute spinal cord injury. Spine 2006;31:E250-253.

4 Coleman WP, Benzel E, Cahill DW, Ducker T, Geisler F, Green B, et al. A Critical appraisal of the reporting of the NASCIS II and III studies of MPSS in acute spinal cord injury. J Spinal Disord 2000;13:185-99.

5 Hadley MN, Walters BC. Pharmacological therapy after acute cervical spinal cord injury. In: Guidelines for the management of acute cervical spine and spinal cord injuries. Neurosurgery 2002;50:S63-S72.

\section{How full is the glass?}

Instead of speculating about our differing methods as the source of our differing conclusions, Turner and Rosenthal instead focused on our adoption of UK's National Institute for Health and Clinical Excellence (NICE) criteria for clinical significance. NICE adopted Cohen's definition of a "medium" effect size (0.5) for clinical significance. ${ }^{12}$ Cohen intended that a medium effect size represent an effect of a size likely to be visible to the naked eye of a careful observer (p 156). By this interpretation, clinical 
significance of antidepressants is reached when a careful observer can see that medicated patients have noticeably lower depression than patients taking placebo. In this light, the NICE criteria seem sensible indeed.

A more appropriate use of Turner and Rosenthal's "d-juice" metaphor (where d-juice is the level of antidepressant efficacy) to explain our findings is that the amount of $d$-juice in the trials was pitifully small or even non-existent when people with less severe depression were examined, but larger when very severely depressed individuals were examined. Yet note that effect sizes (in their $\mathrm{d}$ form) can in theory take values as large as infinity. ${ }^{3}$ Thus, even the medium effect size observed for trials that sampled extremely depressed individuals could be viewed as inconsequential.

In considering treatment for depressed patients, should clinicians be content that antidepressants attain the clinical significance criterion only for the most severely depressed patients? Even following drug (or placebo) therapy, the average patient can still be characterised as depressed (see reference 5 for the logic on this inference ${ }^{4}$ ). Consequently, it seems unsafe to assume that antidepressants will fully succeed for the average severely depressed patient. In short, this trickle of "d-juice" is likely to leave a depressed patient thirsty and looking for alternative means to fill the proverbial glass.

Irving Kirsch professor of psychology, University of Hull, Hull HU67RX

I.Kirsch@hull.ac.uk

Blair T Johnson professor of psychology, Department of Psychology and Center for Health, Intervention, and Prevention, University of Connecticut, Storrs, Connecticut, USA Competing interests: IK has received consulting fees from Squibb and Pfizer. BTJ has no competing interests except that he was, with IK, an author on the article to which Turner and Rosenthal (2008) reacted.

1 Turner EH, Rosenthal R. Efficacy of antidepressants: Is not an absolute measure, and it depends on how clinical significance is defined. BMJ 2008;336:516-7 (8 March), doi:10.1136/bmj.39510.531597.80.

2 Cohen J. A power primer. Psychol Bull 1992;112:155-9.

3 Johnson BT, Eagly AH. Quantitative synthesis of social psychological research. In: Reis HT, Judd CM, eds. Handbook of research methods in social and personality psychology. London: Cambridge University Press, 2000:496-528.

4 Jacobson NS, Truax, P. Clinical significance: a statistical approach to defining meaningful change in psychotherapy research. J Consult Clin Psychol 1991;59:12-9.

\section{DEGENERATIVE AORTIC STENOSIS}

\section{Antiobiotic prophylaxis is different in guidelines}

Ramaraj and Sorrell recommend antibiotic prophylaxis for infective endocarditis in all patients with aortic stenosis. ${ }^{1}$ This advice is not in accordance with the most recent

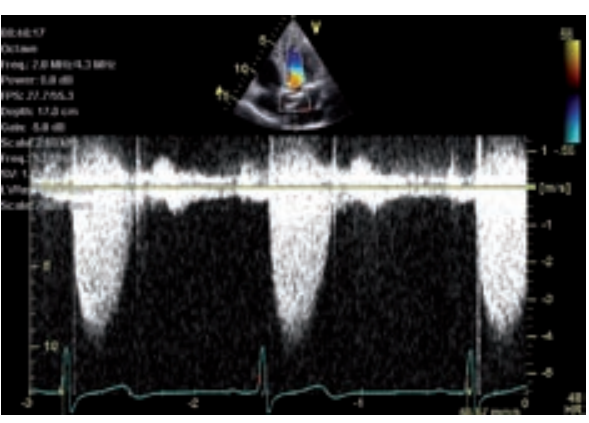

guidelines by the American Heart Association on prevention of infective endocarditis. ${ }^{2}$

According to these guidelines, antibiotic prophylaxis is indicated only for certain cardiac conditions with the highest risk of infective endocarditis. These include prosthetic heart valves or prosthetic material used for cardiac valve repair, previous infective endocarditis, unrepaired cyanotic congenital heart disease (CHD), completely repaired congenital heart defect with prosthetic material, or CHD with residual defect at the site or adjacent to the site of a prosthetic patch, and cardiac transplant patients who develop cardiac valvulopathy.

These guidelines are based on the results of latest research that indicate that few cases of infective endocarditis would be preventable with antibiotic prophylaxis, even with $100 \%$ effectiveness assumed. ${ }^{3}$ They also indicate that most patients with endocarditis on a known cardiac lesion do not develop the disease as a consequence of a dental or medical procedure. Thus in one study, endocarditis developed within 30 days of a procedure in only 25 (12.7\%) of 197 patients who had had heart disease. Nine out of 10 patients with heart disease contracted endocarditis in some other way. ${ }^{4}$

The current guidelines are evidence based as opposed to the previous guidelines, which were at best based only on consensus opinion of experts, case studies, or standards of care. Thus antibiotic prophylaxis is no longer recommended for any other form of CHD, except for the conditions listed above.

Habib U Rehman clinical assistant professor, Regina Qu’Appelle Health Region, Regina, Saskatchewan, Canada S4S OA5 habib31@sasktel.net

Competing interests: None declared.

1 Ramaraj R, Sorrell V. Degenerative aortic stenosis. BMJ 2008;336:550-5.

2 Wilson W, Taubert KA, Gewitz M, Lockhart PB, Baddour LM, Levison M, et al. American Heart Association Rheumatic Fever, Endocarditis, and Kawasaki Disease Committee. American Heart Association Council on Cardiovascular Disease in the Young. American Heart Association Council on Clinical Cardiology. American Heart Association Council on Cardiovascular Surgery and Anesthesia. Quality of Care and Outcomes Research Interdisciplinary Working Group. Prevention of infective endocarditis. Circulation 2007;116:1736-54.
3 Strom BL, Abrutyn E, Berlin JA, Kinman JL, Feldman RS, Stolley PD, et al. Dental and cardiac risk factors for infective endocarditis: a population-based, case-control study. Ann Intern Med 1998;129:761-9.

4 van der Meer JTM, van Wijk W. Lancet 1992;339:135-9.

\section{ASSESSING THE ABILITY TO WORK}

\section{How helpful is disability label?}

I write with reference to Verbeek and van Dijk. ${ }^{1}$ For incapacity benefit, where no "factual evidence" is available, the assessment is based entirely on what the claimant states in a questionnaire, and how they perform on the day of the assessment. ${ }^{12}$ In other words, they have an incapacity if they say they do and if they perform appropriately.

The Disability Discrimination Act 1995 (DDA) defines disability as a substantial impairment in normal daily activities that is long term. The disability can be physical or mental, but the need for the mental impairment to be related to a recognised medical condition was removed in the 2004 amendment to the act, mostly as a result of intense lobbying by the then Disability Rights Commission.

Currently an individual can therefore be regarded as disabled if they believe they are disabled, and behave as if they are, for a period of a year. There is no requirement for them to have any reason to be disabled in the sense that they have an underlying disease process or obvious physical or mental impairment. Illness behaviour such as this often leads to inappropriate prescribing and treatment as well as long term unemployment, all potentially harmful.

Any "evaluation" ${ }^{1}$ is likely to focus on secondary gain and illness behaviour. What evidence there is indicates that these could be factors in as many as $75 \%$ of incapacity benefit claimants ${ }^{3}$ and therefore likely to be factors in a sizeable proportion of individuals who believe they are disabled under the DDA. This would inevitably raise major questions about the DDA itself.

Although these may be issues for government and society to tackle, doctors should be asking more challenging questions about the harmful effects such a liberal approach to defining disability and incapacity can have.

Anthony N Williams consultant occupational physician, Working Fit Limited, PO Box 389, Temple Ewell, Dover CT169BF tonywilliams@workingfit.com

Competing interests: None declared.

1 Verbeek J, van Dijk F. Assessing the ability to work. BMJ 2008;336:519-20. (8 March.)

2 Henderson M. Transformation of the personal capability assessment. London: Department of Work and Pensions, 2007. www.dwp.gov.uk/welfarereform/tcpa.pdf

3 Waddell G. Models of disability, using low backpain as an example. London: Royal Society of Medicine Press, 2002. 